\title{
Expression of Eph receptors and their ligands, ephrins, during lipopolysaccharide fever in rats
}

\author{
Andrei I. Ivanov, ${ }^{1,2}$ Alexandre A. Steiner, ${ }^{1}$ Adrienne C. Scheck, ${ }^{3}$ and Andrej A. Romanovsky ${ }^{1}$ \\ ${ }^{1}$ Systemic Inflammation Laboratory, Trauma Research, St. Joseph's Hospital, Phoenix, Arizona; \\ ${ }^{2}$ Department of Pathology and Laboratory Medicine, Emory University, Atlanta, Georgia; and ${ }^{3}$ Neurology \\ and Neurosurgery Research, Barrow Neurological Institute, St. Joseph's Hospital, Phoenix, Arizona
}

Submitted 19 February 2004; accepted in final form 24 January 2005

Ivanov, Andrei I., Alexandre A. Steiner, Adrienne C. Scheck, and Andrej A. Romanovsky. Expression of Eph receptors and their ligands, ephrins, during lipopolysaccharide fever in rats. Physiol Genomics 21: 152-160, 2005. First published January 25,2005; doi;10.1152/physiolgenomics.00043.2004.-Erythropoietinproducing hepatocellular (Eph) receptor tyrosine kinases and their ligands, ephrins, are involved in embryogenesis and oncogenesis by mediating cell adhesion and migration. Although ephrins can be induced by bacterial LPS in vitro, whether they are involved in inflammation in vivo is unknown. Using differential mRNA display, we found that a febrigenic dose of LPS (50 $\mu \mathrm{g} / \mathrm{kg}$ iv) induces a strong transcriptional upregulation of ephrin-A1 in rat liver. We confirmed this finding by real-time RT-PCR. We then quantified the mRNA expression of different ephrins and Eph receptors at phases 1-3 of LPS fever in different organs. Febrile phases 2 (90 min post-LPS) and 3 (300 $\mathrm{min}$ ) were characterized by robust upregulation (up to 16-fold) and downregulation (up to 21-fold) of several ephrins and Eph receptors. With the exception of EphA2, which showed upregulation in the brain at phase 2, expressional changes of Eph receptors and ephrins were limited to the LPS-processing organs: liver and lung. Characteristic, counter-directed changes in expressional regulation of Eph receptors and their corresponding ligands were found: upregulation of EphA2, downregulation of ephrin-A1 in the liver and lung at phase 2; downregulation of EphB3, upregulation of ephrin-B2 in the liver at phase 2; downregulation of EphA1 and EphA3, upregulation of ephrins-A1 and -A3 in liver at phase 3. In the liver, transcriptional changes of EphA2 and EphB3 at phase 2 were confirmed at protein level. These coordinated, phase-specific responses suggest that different sets of ephrins and Eph receptors may be involved in cellular events (such as disruption of tissue barriers and leukocyte transmigration) underlying different stages of systemic inflammatory response to LPS.

systemic inflammation; endotoxin; receptor tyrosine kinases

EPHRINS ARE MEMBRANE-BOUND LIGANDS of the so-called erythropoietin-producing hepatocellular (Eph) receptors, the biggest family of receptor tyrosine kinases (for reviews, see Refs. 19, 30, 47). Ephrins (from Eph family receptor-interacting ligands) are divided into two subclasses, A and B. All five ephrins of the A subclass (A1-A5) are tethered to the membrane via a glycosylphosphatidylinositol anchor, whereas all three ephrins of the B subclass (B1-B3) are integral membrane proteins. There are also two subclasses of Eph receptors, $\mathrm{A}$ and $\mathrm{B}$, that correspond to the two subclasses of ligands. All eight members of the A receptor subclass (EphA1-EphA8) interact with all

Article published online before print. See web site for date of publication (http://physiolgenomics.physiology.org).

Address for reprint requests and other correspondence: A. A. Romanovsky, Systemic Inflammation Laboratory, Trauma Research, St. Joseph's Hospital, 350 W. Thomas Rd., Phoenix, AZ 85013 (E-mail: aromano@chw.edu).
ephrin-A ligands; all six members of the $\mathrm{B}$ receptor subclass (EphB1-EphB6) bind all ephrin-B ligands. Because all ephrins and Eph receptors are membrane-associated proteins, a direct cell-cell contact is required for receptor activation. Whereas ligand binding to other receptor tyrosine kinases induces signaling only in the receptor-bearing cell, the ephrin-Eph binding triggers signaling in both the receptor-bearing cell ("forward" signaling) and the ligand-bearing cell ("reverse" signaling) (12, 19, 30). Transduction of reverse signals by ephrins of the B subclass involves the phosphorylation of the cytoplasmic tail of the ephrin-B molecule. Ephrin-A ligands lack a cytosolic domain and initiate reverse signaling by clustering into membrane lipid rafts. Bidirectional signaling triggered by ephrinEph can promote both the repulsion and attraction of the involved cells (Refs. 19, 30, 47; also see DISCUSSION).

A major insight into the biological function of ephrins and Eph receptors has come from studies of embryogenesis: these proteins have been found to play prominent roles in the formation of tissue boundaries, neural crest cell migration, axon guidance, and angiogenesis (10, 19, 30, 47). Although ephrins and Eph receptors are expressed in tissues of adult mammals, the functions of these molecules in the postnatal period remain enigmatic. Interestingly, the first member of the ephrin family, ephrin-A1 (previously known as B61 protein), was identified as an immediate early response gene induced in cultured endothelial cells by bacterial lipopolysaccharide (LPS) and proinflammatory cytokines, such as tumor necrosis factor (TNF)- $\alpha$ and interleukin (IL)-1 $\beta(14,16)$. Subsequent in vitro studies revealed the expressional regulation of other ephrins (A5 and B1) and some of the Eph receptors (EphA2 and EphA3) by TNF- $\alpha$ and IL-1 $\beta$ in different cell lines $(5,21$, $22,41)$. Nothing is known about the involvement of ephrins or Eph receptors in inflammation in vivo.

The present study started with a serendipitous observation. By using a differential display of mRNA from the rat liver, we have discovered that ephrin-A1 is one of a very few genes strongly upregulated by a mild dose of intravenous LPS. We then conducted a systematic, quantitative RT-PCR analysis of the expression of different ephrins and Eph receptors in tissues of rats treated with this dose of LPS.

Mild doses of LPS are known to cause a polyphasic febrile response: at least three distinct febrile phases (phases 1-3) have been identified in rats and mice $(33,39,40,42)$. The division of the systemic inflammatory response to LPS into three febrile phases is important. Indeed, different phases are characterized by different behavioral manifestations (so-called sickness symptoms; for review, see Ref. 36). For example, phase 1 is associated with hyperalgesia/allodynia and motor hyperactivity, whereas phase 2 is associated with hypoalgesia 
and sleepiness (38). Humoral and neural mechanisms of the immune system-to-brain signaling contribute differently to different febrile phases (46). Furthermore, the three phases are characterized by distinct patterns of gene expression $(17,18)$. All three phases were studied in the present work.

\section{MATERIALS AND METHODS}

\section{Animals and Surgical Preparation}

Seventy-two 2-mo-old male inbred Wistar Kyoto rats (Harlan Sprague-Dawley, Indianapolis, IN) were used in this study. All rats were initially housed three per standard "shoebox;" after surgery, they were caged singly. The room was on a light-dark cycle of 12:12 h (lights on from 7 AM to 7 PM). Food (Teklad Rodent Diet "W" 8604; Harlan Teklad, Madison, WI) and water were available ad libitum. Each animal was subjected to chronic jugular catheterization. The surgery was performed under ketamine-xylazine-acepromazine (55.6, 5.5 , and $1.1 \mathrm{mg} / \mathrm{kg}$, respectively, ip) anesthesia, as described elsewhere (40). Briefly, a silicone catheter was passed into the superior vena cava through the jugular vein, and the free end of the catheter was exteriorized at the nape. On day 1 postsurgery, the catheter was flushed with heparinized $(50 \mathrm{U} / \mathrm{ml})$ saline; on day 3 , the rat was used in an experiment. All experiments were started between 8 and 9 AM. This study was approved by the St. Joseph's Hospital and Medical Center Animal Care and Use Committee.

\section{Tissue Harvesting}

Protocol 1. This protocol was designed to collect liver samples for differential mRNA display. Six rats in their cages were transferred to a climatic chamber (Forma Scientific, Marietta, $\mathrm{OH}$ ) set to a temperature of $29^{\circ} \mathrm{C}$ and $50 \%$ relative humidity (these conditions correspond to the thermoneutral zone for Wistar rats; see Ref. 37). After a 1-h stabilization period, three rats were injected with Escherichia coli 0111:B4 LPS (Sigma-Aldrich, St. Louis, MO; $50 \mu \mathrm{g} / \mathrm{kg}$ iv) and three others with saline $(1 \mathrm{ml} / \mathrm{kg}$ iv). The 300 -min postinjection time point (corresponds to phase 3 of the febrile response) was selected for tissue harvesting. At this point, each rat was anesthetized with a small dose of ketamine-xylazine-acepromazine cocktail $(5.6,0.6$, and $0.1 \mathrm{mg} / \mathrm{kg}$, respectively, iv) and removed from the chamber. The thoracic cavity was opened, and the rat body was perfused through the left ventricle of the heart (right atrium cut) with $30 \mathrm{ml}$ of saline followed by $30 \mathrm{ml}$ of an RNA-preserving solution [RNAlater (Ambion, Austin, TX) diluted 1:1 with saline]. Samples of the liver were harvested and snap frozen in liquid nitrogen.

Protocol 2. For quantifying the expression of ephrins and Eph receptors by real-time RT-PCR, samples of the liver, lung, and brain (hypothalamus) were harvested according to protocol 2. Seven groups of rats (6 animals/group) were instrumented as in protocol 1. Three groups were injected with LPS $(50 \mu \mathrm{g} / \mathrm{kg}$ iv) and three groups with saline $(1 \mathrm{ml} / \mathrm{kg}$ iv), and one group remained untreated. The rats treated with LPS or saline were anesthetized for tissue harvesting at 30,90, and 300 min postinjection. As reported in our recent study using the same model (18), these time points correspond to the maximal rate of body temperature rise at each of the three febrile phases. The untreated controls were anesthetized at a time point corresponding to the time of LPS or saline injection in the other six groups $(0 \mathrm{~min})$. This design permitted expressing the results obtained in the LPS- and saline-treated rats relative to the untreated controls, thus accounting for potential circadian dynamics in gene expression. Each rat was then perfused as in protocol 1, and samples of the liver and right lung were collected and snap frozen in liquid nitrogen. The rat was then decapitated, the brain was removed, and the entire hypothalamus was dissected and frozen. All samples were stored at $-80^{\circ} \mathrm{C}$.

Protocol 3. This protocol was designed to collect liver samples from 12 LPS-treated and 12 saline-treated rats for immunoblotting.
The purpose of this experiment was to confirm at the protein level the principal changes (i.e., those at febrile phases 2 and 3 ) found at the mRNA level in the RT-PCR experiment. This protocol was identical to protocol 2 except for two details. First, tissue harvesting was delayed by $20 \mathrm{~min}$ compared with the corresponding time points in protocol 2, i.e., the rats were anesthetized at $110 \mathrm{~min}$ (phase 2) or 320 min (phase 3) after administration of LPS or saline. Second, no RNA-preserving solution was used for perfusion.

\section{RNA Isolation}

Total RNA was isolated from the tissue samples using RNeasy kits (Qiagen, Valencia, CA) and treated with DNase I (Ambion). Its purity was verified by finding that the 260:280-nm absorption ratio was $>1.9$; its integrity was confirmed by the presence of two well-defined $28 \mathrm{~S}$ and $18 \mathrm{~S}$ rRNA electrophoretic bands. The amount of the isolated RNA was quantified by absorption at $260 \mathrm{~nm}$. For a more detailed description, see Ref. 17.

\section{Differential Display of $m R N A$}

RT-PCR and electrophoresis. Differential display was performed using a Hieroglyph mRNA Profile and FluoroDD kits (Beckman Coulter, Fullerton, CA) according to manufacturer's instructions (also see Ref. 23). Briefly, four subpopulations of cDNA were generated from each RNA sample using SuperScript II RT (Invitrogen, Carlsbad, CA) and four different "anchored" primers (AP) represented by oligo(dT) primers linked to a T7 promoter-derived sequence. The RT reaction was performed using $10 \mathrm{ng} / \mu \mathrm{l}$ total RNA, $2 \mathrm{U} / \mu \mathrm{l}$ enzyme, 0.2 $\mu \mathrm{M}$ AP, and a mixture of fluorophore-labeled dNTPs (20 $\mu \mathrm{M}$ each) in a total volume of $20 \mu \mathrm{l}$. The same AP was used as a $3^{\prime}$-primer in the subsequent PCR reaction in a combination with a $5^{\prime}$-arbitrary primer (ARP; a random decamer containing a fragment of the M13 sequence). The PCR reaction was performed by adding $2 \mu \mathrm{l}$ of the RT product to $18 \mu \mathrm{l}$ of a solution containing $0.2 \mu \mathrm{M} \mathrm{AP}, 0.2 \mu \mathrm{M}$ ARP, $0.05 \mathrm{U} / \mu \mathrm{l}$ AmpliTaq DNA polymerase (Applied Biosystems, Foster City, CA), and fluorophore-labeled dNTPs (20 $\mu \mathrm{M}$ each). Both the RT reaction and PCR reaction were conducted in a Perkin Elmer 9700 thermal cycler (Applied Biosystems). Each PCR sample $(7 \mu \mathrm{l})$ was mixed with a sample-loading dye $(4 \mu \mathrm{l})$, incubated at $95^{\circ} \mathrm{C}$ for $2 \mathrm{~min}$ to cause RNA denaturation, and loaded onto a $4.5 \%$ urea-polyacrylamide gel. All samples were loaded in duplicate. The electrophoresis was run on a Genomyx LR Programmable DNA Sequencer (Beckman Coulter) for $6 \mathrm{~h}$. The gel was dried, and DNA fragments were visualized using Genomyx SC Fluorescent Scanner (Beckman Coulter).

Identification of differentially expressed DNA fragments. When a band showed a differential expression in all LPS-treated rats compared with saline-treated rats, this band was excised from the gel, and the corresponding cDNA fragment was eluted from the agarose by incubation $\left(50^{\circ} \mathrm{C}, 1 \mathrm{~h}\right)$ in $0.1 \mathrm{M}$ Tris-EDTA buffer $(\mathrm{pH} 7.0)$. The eluted product was reamplified by PCR using the same AP-ARP pairs as for the differential display. The reamplified DNA fragments were run on a $1 \%$ agarose gel, excised, and purified with a QIAquick PCR purification kit (Qiagen). A unidirectional sequencing reaction was then performed on an ABI 377 automated DNA sequencer (Applied Biosystems) using either T7 or M13 primer and an ABI Prism BigDye terminator-sequencing kit according to the manufacturer's instructions. The obtained sequence was compared with entries in GenBank using the BLAST program.

\section{Real-Time RT-PCR}

The isolated RNA was reverse transcribed to cDNA by oligo(dT) priming using a GeneAmp RNA PCR kit (Applied Biosystems) and SuperScript II RT. Hepatic and pulmonary RNA samples were $2 \mu \mathrm{g}$ each, and all hypothalamic samples were $1 \mu \mathrm{g}$ each; the reaction volume was $20 \mu$ l. Real-time PCR was performed using a LightCycler (Roche Molecular Biochemicals, Indianapolis, IN). The concentration 
of double-stranded cDNA after each cycle of amplification was monitored by SYBR Green I fluorescence (13). Primers for the genes of interest and for glyceraldehyde-3-phosphate dehydrogenase (GAPDH), a housekeeping gene, were found in the literature (Table 1) or designed, based on the rat or mouse sequences deposited in GenBank. Sample preparation and detailed protocols for PCR are described elsewhere (17). The size of the amplicon (Table 1) was verified by agarose gel electrophoresis. For each gene of interest, the PCR products obtained from liver samples were independently identified by sequencing (see Identification of differentially expressed DNA fragments above). From each tissue, 16 randomly selected RNA samples were run together in each RT-PCR: two from each of the three LPS-treated groups, two from each of the three saline-treated groups, two from the untreated group, and two additional samples (1 from saline- and the other from LPS-treated group) with no RT enzyme added (so-called "-RT" controls). Because samples from only two animals from each group were used in one real-time RT-PCR, three independent runs of real-time RT-PCR were performed in duplicates for each tissue. The results of the RT-PCR analysis were visualized by electrophoresis. At the exponential phase of amplification, the PCR reactions were stopped. The amplicons were separated in a $1.5 \%$ agarose gel and stained with SYBR Gold nucleic acid (Molecular Probes, Eugene, OR).

\section{Immunoblotting}

Tissue samples were homogenized in T-PER tissue protein extraction reagent (Pierce, Rockford, IL) containing Halt protease inhibitor cocktail (Pierce) and phenylmethylsulfonyl fluoride (PMSF; $1 \mathrm{mmol} / \mathrm{l}$, Sigma-Aldrich). Homogenates were cleared by centrifugation $(14,000$ $g, 20 \mathrm{~min}, 4^{\circ} \mathrm{C}$ ). The supernatants were boiled in SDS buffer (BioRad, Hercules, CA), subjected to electrophoresis in SDS-polyacrylamide gel (10-20 $\mu \mathrm{g}$ of total protein per lane), and transferred to a nitrocellulose membrane (Bio-Rad). The membranes were blocked with $5 \%$ milk in Tris-buffered saline ( $\mathrm{pH} 8.0$ ) containing $0.1 \%$ Tween 20. Thereafter, they were incubated overnight at $4{ }^{\circ} \mathrm{C}$ with one of the following primary antibodies (diluted in the blocking solution): rabbit polyclonal anti-ephrin-A1 $(1: 1,000)$, rabbit polyclonal anti-ephrin-B2
$(1: 1,000)$, rabbit polyclonal anti-EphA3 (1:500), goat polyclonal antiEphB3 (1:500; all from Santa Cruz Biotechnology, Santa Cruz, CA), rabbit monoclonal anti-EphA2 (1:500; Upstate, Charlottesville, VA), and rabbit polyclonal anti- $\beta$-actin antibody (1:1,000; Sigma-Aldrich). The membranes were washed with Tris-Tween 20 buffer and incubated $\left(30 \mathrm{~min}, 20^{\circ} \mathrm{C}\right)$ with appropriate horseradish peroxidase-conjugated secondary antibodies (Jackson Immunoresearch, West Grove, PA). The blots were developed using an Enhanced Chemiluminescence Reagent (Amersham, Buckinghamshire, UK) and X-ray film (Hyperfilm ECL, Amersham). Digital images of the developed films were acquired using a NucleoVision gel documentation system (NucleoTech, San Carlos, CA). The intensity of each band (background subtracted) was quantified using the GelExpert software (NucleoTech).

\section{Data Processing and Analysis}

As in a previous study (18), the relative expression $R$ of each gene of interest was calculated as follows

$$
R_{i, t}=2^{\left(N_{h, t}-N_{h, c}\right)-\left(N_{i, t}-N_{i, c}\right)} \times 100(\%)
$$

where $N$ is the threshold cycle number, i.e., the number of the amplification cycle in which the fluorescence of a given sample becomes significantly different from the baseline signal. The indexes $i$ and $h$ refer to the gene of interest (one of the ephrins or Eph receptors) and the housekeeping gene (GAPDH), respectively. The index $t$ refers to a sample from a treated (with either LPS or saline) rat. The index $c$ refers to the samples from the two untreated controls run in the same real-time RT-PCR (the variables $N_{i, c}$ and $N_{h, c}$ are the means of the two controls). Equation 1 is based on the inverse proportionality between $N$ and $\log _{2} \mathrm{C}$, where $\mathrm{C}$ is the initial template concentration in the PCR sample (8). Hence the physical meaning of $R_{i, t}$ is the concentration of mRNA of interest in a sample from a treated animal divided by the concentration of the same message in the simultaneously run samples from untreated controls, where each concentration is normalized for the concentration of GAPDH message in the same sample.

Table 1. Primers used for real-time RT-PCR

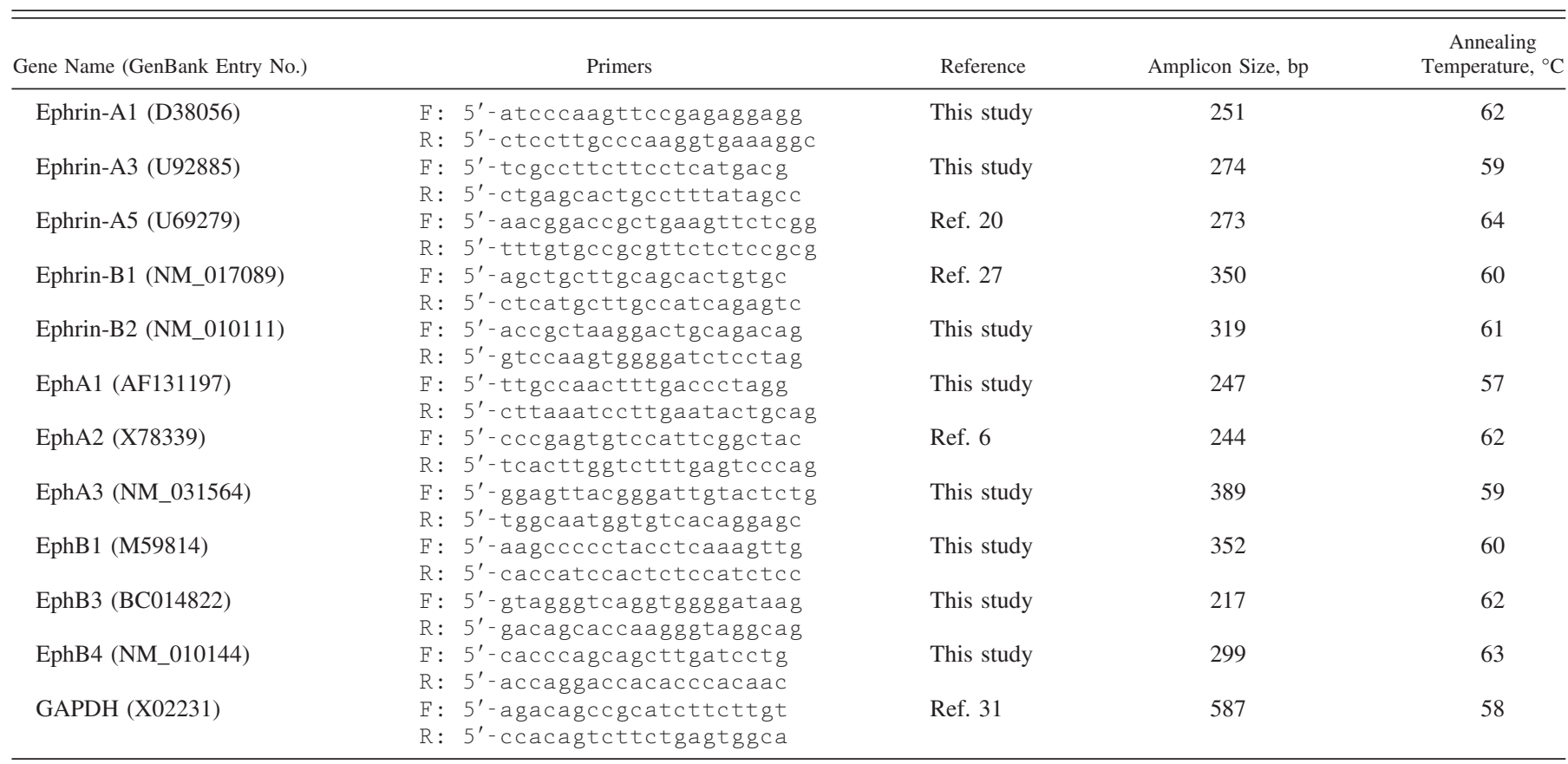

F, forward; R, reverse. 
The relative expression of each protein of interest was calculated as the ratio between the intensities of two immunoblotting bands of the same tissue sample: one corresponding to the protein of interest and the other to the housekeeping protein, $\beta$-actin.

The relative transcriptional expression data for each gene were compared across treatments (LPS vs. saline) and time points (30, 90, and $300 \mathrm{~min}$ ) by two-way ANOVA followed by Newman-Keuls post hoc test. The relative protein expression data were compared across treatments (LPS vs. saline) by Student's $t$-test. All analyses were performed using Statistica AX'99 (StatSoft, Tulsa, OK). All data are presented as means $\pm \mathrm{SE}$.

\section{RESULTS}

\section{Differential mRNA Display}

Samples of mRNA isolated from the liver of LPS- and saline-treated rats were compared by differential display by using eight combinations of primers (4 APs $\times 2$ ARPs). Representative results obtained with two pairs of primers are shown in Fig. 1. Almost all bands had similar intensity in the samples from LPS- and saline-treated rats, thus indicating that the mild dose of LPS used $(50 \mu \mathrm{g} / \mathrm{kg})$ did not affect the expression of the majority of genes in the rat liver (Fig. 1). Only eleven bands appeared differentially expressed (7 upregulated and 4 downregulated) in all LPS-treated samples compared with all saline-treated controls. The cDNA from each band showing upregulation was isolated, reamplified, and se-

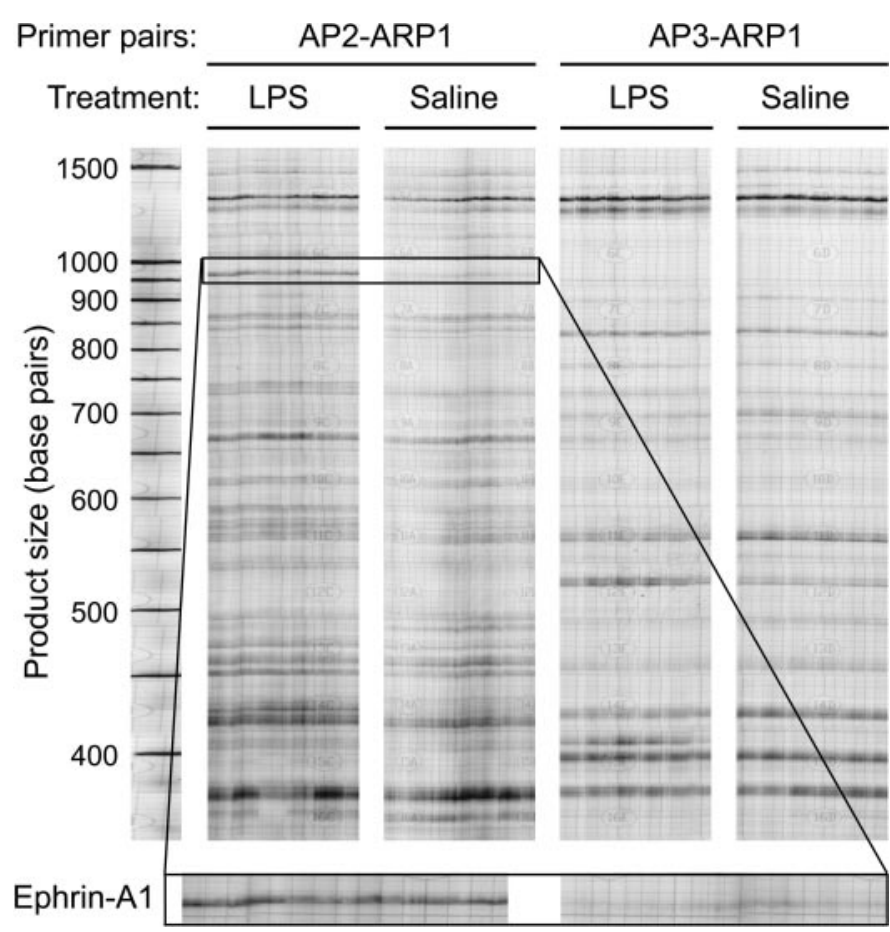

Fig. 1. Differential display of mRNA amplified from the liver of Wistar Kyoto rats injected with either LPS $(50 \mu \mathrm{g} / \mathrm{kg}$ iv) or saline $(1 \mathrm{ml} / \mathrm{kg}$ iv) $300 \mathrm{~min}$ before harvesting the samples. RT-PCR was performed on total liver RNA using 2 different "anchored" primer (AP)-"arbitrary" primer (ARP) pairs. Heat-denatured RT-PCR products were run on a urea-polyacrylamide gel and visualized as described in the text (see Differential Display of $m R N A$ ). For each pair of primers shown, the area marked as LPS corresponds to samples from 3 LPS-treated rats loaded in duplicates (6 wells in total); the area marked as Saline corresponds to samples from 3 saline-treated rats loaded in duplicates (6 wells in total). The enlarged band shows the upregulation of the ephrin-A1 amplicon in the samples from LPS-treated rats. quenced. High-quality sequences were obtained for five fragments: three well-known acute-phase proteins (viz., $\gamma$-chain of fibrinogen and apolipoproteins $\mathrm{A}$ and $\mathrm{J}$ ), a product that did not match with any sequence in GenBank, and the mouse ephrin-A1 (Fig. 1, enlarged band). Because the transcriptional upregulation of ephrin-A1 is a previously unknown in vivo effect of LPS, we next analyzed the expression of this gene in the rat liver, lung, and hypothalamus at different phases of the febrile response to LPS.

\section{Real-Time RT-PCR}

Expression of ephrin-Al in different organs during LPS fever. The ephrin-A1 transcript was detected in all organs studied; in no organ was its concentration affected by the injection of saline (see Fig. $2 A$ for representative bands on the electrophoretogram and Fig. $2 B$ for results of the quantitative analysis). In the liver, LPS caused biphasic changes of the mRNA level of ephrin-A1: an approximately threefold downregulation (as compared with the time-matched saline-treated rats) at phase 2 was followed by a fourfold upregulation at phase 3. [Body temperature curves showing different febrile phases in this model of fever are published elsewhere (18).] The concentration of the ephrin-A1 transcript in the lung decreased approximately twofold at phase 2 and then returned to the level seen in the saline-treated rats. No effect of LPS on ephrin-A1 expression was found in the hypothalamus.

Expression of ephrins of the A and B subclasses in the liver. Because the largest changes in the expression of ephrin-A1 were found in the liver, we next studied effects of LPS on the expression of other ephrins in this organ. In addition to the ephrin-A1 transcript, transcripts of two other ephrin-A ligands (A3 and A5) and two ephrin-B ligands (B1 and B2) were detected in this organ (Fig. 3A). Although we used several primers and varied the reaction conditions, all attempts to find amplicons of ephrin-A2, ephrin-A4, and ephrin-B3 in the liver failed (data not shown). The expression of ephrin-A3 was upregulated approximately threefold at phase 3 of LPS fever, the expression of ephrin-B2 was upregulated twofold at phase 2 and then returned to the baseline, and the expression of ephrin-A5 and ephrin-B1 was unaffected by LPS (Fig. 3B).

Expression of the Eph receptors of the $A$ and $B$ subclasses in the liver. We next asked whether LPS affects the expression of ephrin receptors in the liver. Transcripts of several receptors representing both the $\mathrm{A}$ and $\mathrm{B}$ subclasses were found. Of the $\mathrm{A}$ subclass, EphA1, EphA2, and EphA3 transcripts were amplified (Fig. 4A), whereas no EphA4, EphA5, EphA6, EphA7, or EphA8 message was detected (data not shown). Of the $B$ subclass, EphB1, EphB3, and EphB4 were amplified (Fig. 4A), whereas no EphB2 message was detected (data not shown). At phase 2, the expression of EphA2 was upregulated $\sim 16$-fold, and the expression of EphB3 was downregulated 4-fold (Fig. 4B). At phase 3 of LPS fever, EphA2 was no longer overexpressed, but receptors EphA1, EphA3, EphB3, and EphB4 were underexpressed ( 4-, 17-, 2-, and 2-fold, respectively).

Transcription of those Eph receptors that showed the strongest overexpression (EphA2), the strongest underexpression (EphA3), or the longest underexpression (EphB3) in the liver 
A

Ephrin-A1

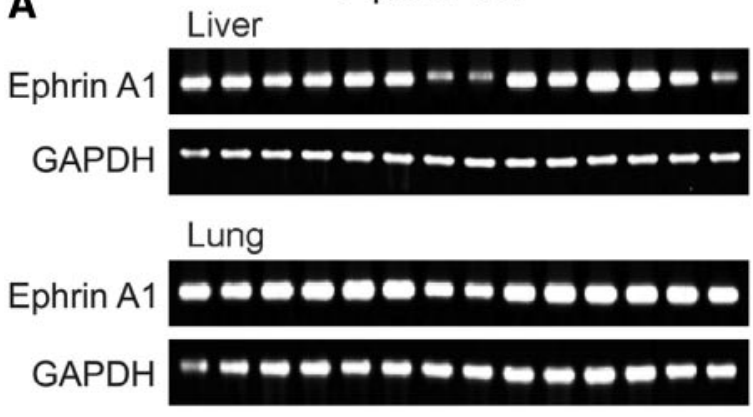

Hypothalamus
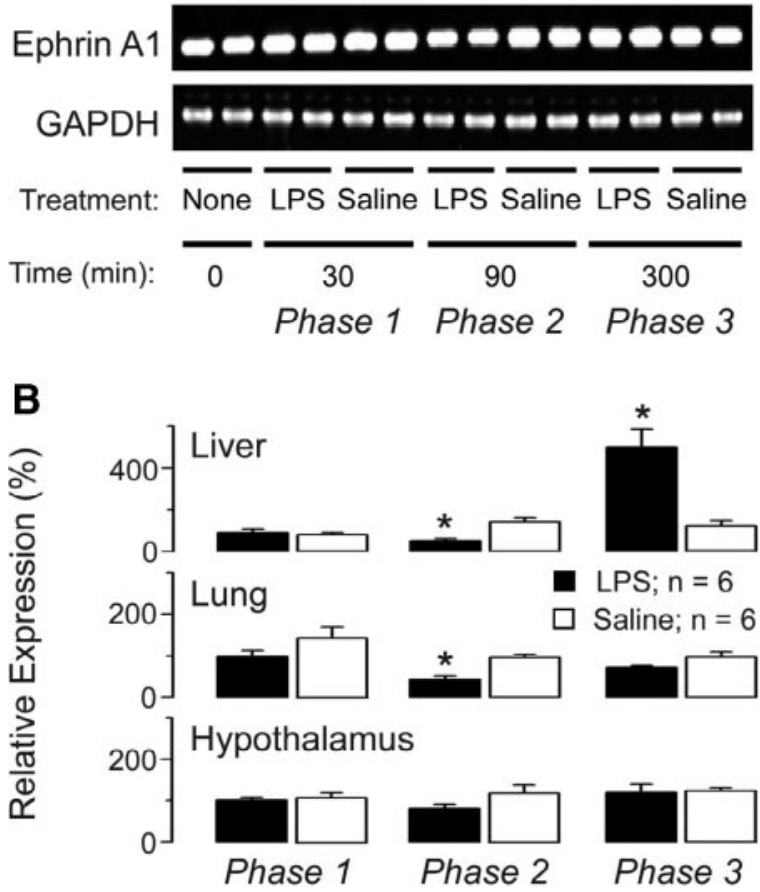

Fig. 2. Effects of LPS and saline on the expression of ephrin-A1 in the liver, lung, and hypothalamus of rats: representative electrophoretograms $(A)$ and the mean relative expression $(B)$. A: electrophoretograms of 14 samples obtained from untreated rats and rats treated with LPS $(50 \mu \mathrm{g} / \mathrm{kg}$ iv) or saline $(1 \mathrm{ml} / \mathrm{kg}$ iv). Time is the time elapsed after LPS or saline injection; phases are the corresponding phases of the febrile response to LPS. The PCR reactions were stopped at the exponential phase of amplification. Amplicons were separated in an agarose gel and visualized by SYBR Gold nucleic acid stain. $B$ : each bar is the mean of 6 individual data points, where each datum represents the concentration of mRNA of interest (ephrin-A1) in a sample from a treated (with LPS or saline) animal divided by the concentration of the same message in the simultaneously run samples from untreated controls, where each concentration is normalized for the concentration of GAPDH message in the same sample (see Data Processing and Analysis). $* P<0.05$.

was confirmed in the same tissue at the protein level and also studied at the mRNA level in the lung and hypothalamus (see below).

Expression of the receptors EphA2, EphA3, and EphB3 in the lung. The changes in expression of all three receptors (viz., EphA2, EphA3, and EphB3) in the lung resembled those in the liver: EphA2 was overexpressed approximately 3 -fold at phase 2, EphA3 was underexpressed 21-fold at phase 3, and EphB2 showed a tendency for underexpression at phase 2 and was 2-fold underexpressed at phase 3 (Fig. 5).
Expression of the receptors EphA2, EphA3, and EphB3 in the hypothalamus. The expression of the same three receptors was studied in the hypothalamus (Fig. 6). The EphA2 transcript level was increased approximately threefold at phase 2, whereas levels of the EphA3 and EphB3 transcripts were unaffected by LPS.

\section{Immunoblotting}

Expression of the receptors EphA2, EphA3, and EphB3 at the protein level in the liver. The expression of these receptors was studied at the protein level in the liver (Fig. 7). The EphA2 protein level was increased approximately threefold at phase 2, the EphA3 level showed a tendency for a decrease (15\%) at phase 3, and the EphB3 protein was downregulated (30\%) at phase 3. Whereas these results confirm at the protein level the pattern of expressional changes of Eph receptors at the mRNA level, the found transcriptional changes of ligands (ephrins) remain unconfirmed due to the low quality of commercially available antibodies. The anti-ephrin-A1 antibody used produced multiple bands, whereas the anti-ephrin-B2 antibody produced the highest-intensity band, corresponding to the molecular mass of $\sim 110 \mathrm{kDa}$ (instead of $60 \mathrm{kDa}$ ).
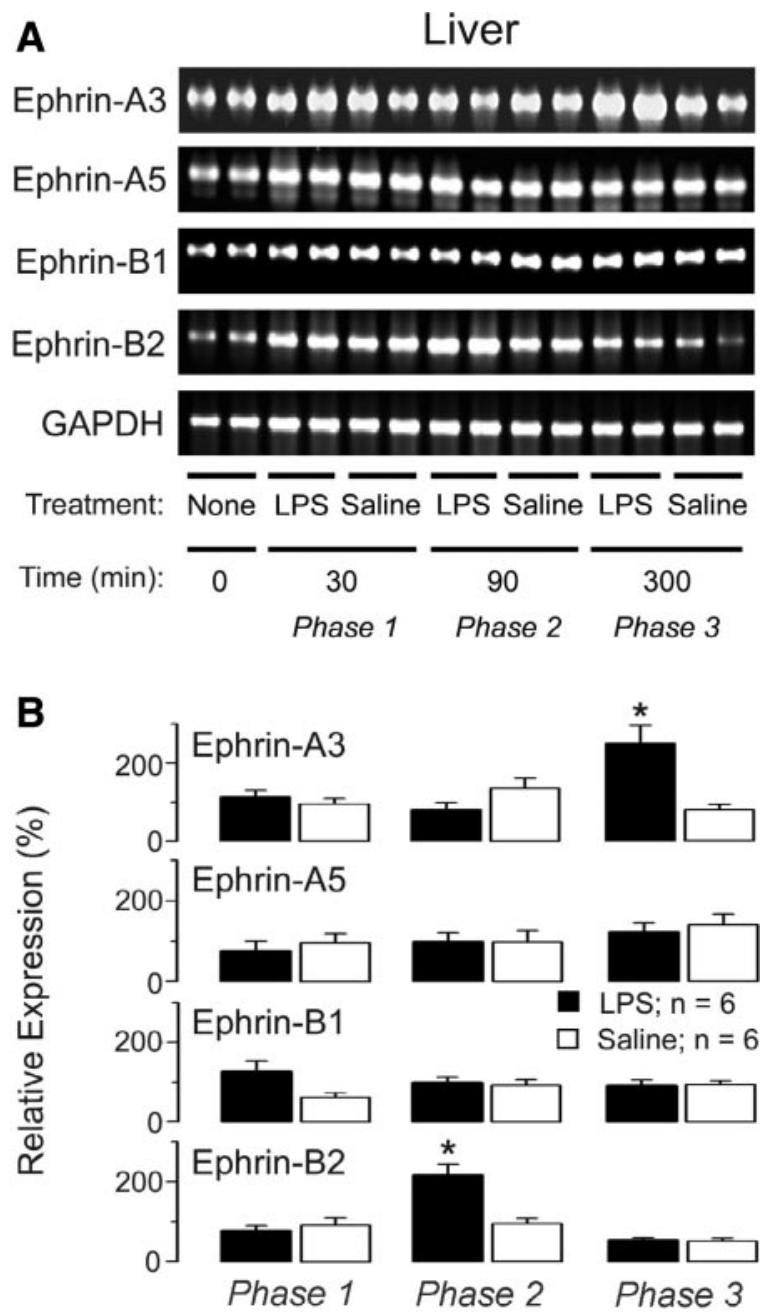

Fig. 3. Effects of LPS and saline on the expression of ephrin genes in the rat liver: representative electrophoretograms $(A)$ and the mean relative expression (B). For details, see the legend to Fig. 2. $* P<0.05$. 
A

Liver

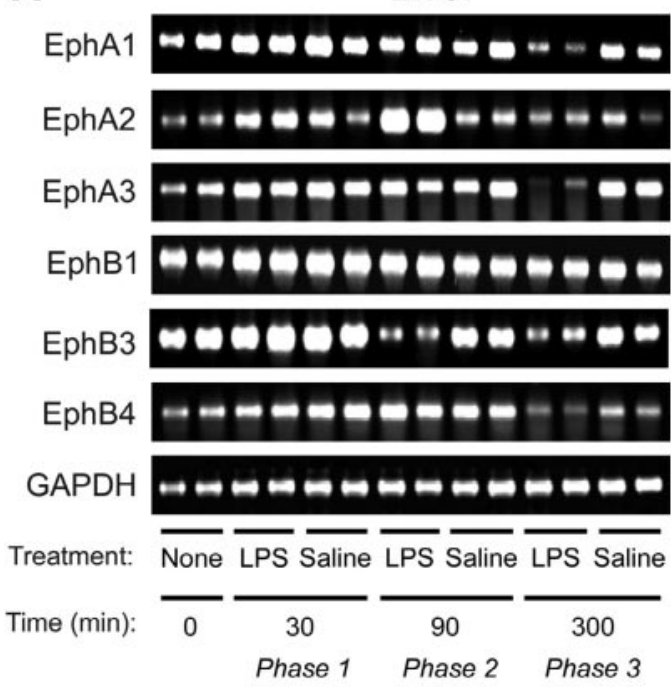

B

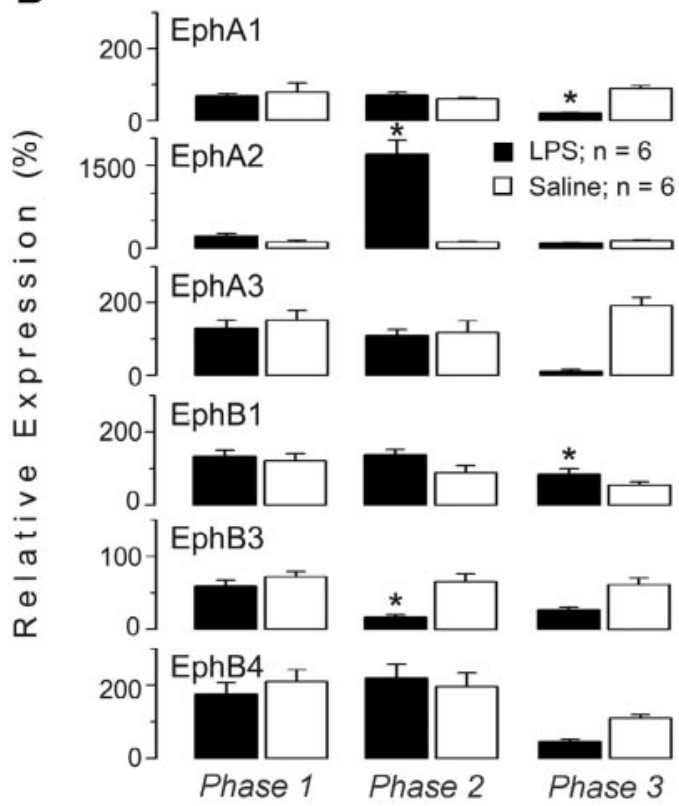

Fig. 4. Effects of LPS and saline on the expression of erythropoietin-producing hepatocellular (Eph) receptor genes in the rat liver: representative electrophoretograms $(A)$ and the mean relative expression $(B)$. For details, see the legend to Fig. 2. ${ }^{*} P<0.05$.

\section{DISCUSSION}

Changes in the Expression of Ephrins and Eph Receptors during LPS Fever

Although a small number of in vitro studies reported that LPS or proinflammatory cytokines induce changes in the expression of some ephrins and Eph receptors in various cell lines $(5,11,14,16,41)$, no data on the expressional regulation of ephrin-A3 and ephrin-B2 or receptors EphA1, EphB3, and EphB4 by inflammatory stimuli are available. It is also unknown whether the ephrin-Eph system is affected by any inflammatory stimulus in vivo. This is the first study of the transcriptional regulation of ephrins and Eph receptors in an in vivo model of systemic inflammation or fever. It shows that a mild febrigenic dose of systemic LPS affects the mRNA expression of selected ephrins (A1, A3, and B2) and Eph receptors (EphA1, EphA2, EphA3, EphB3, and EphB4) in the rat. Specifically, ephrin-A3 and ephrin-B2 and the receptor EphA2 are upregulated; receptors EphA1, EphA3, EphB3, and EphB4 are downregulated; and ephrin-A1 is first downregulated (at febrile phase 2) and then upregulated (at phase 3) by LPS. The revealed changes are relatively fast (present at febrile phase 2, i.e., $90 \mathrm{~min}$ post-LPS), robust (up to 16-fold upregulation and 21-fold downregulation), and to a certain extent tissue specific: most of the changes are limited to the liver and lung (i.e., the organs involved in LPS processing) and do not occur in the hypothalamus. The principal changes found in the expression of Eph receptors in the liver at the mRNA level also occur at the protein level, where they reveal themselves as a strong upregulation of EphA2, downregulation of EphB3, and tendency for downregulation of EphA3.

Another trait of the expressional changes found, i.e., that Eph receptors and their ligands are often affected in a coordinated fashion, deserves a special discussion. We noticed that the expression of Eph receptors of the subclass A is often decreased (e.g., EphA1 and EphA3 in the liver at phase 3; Figs. 4 and 7) when the expression of their ligands is increased (ephrin-A1 and ephrin-A2 in the liver at phase 3; Figs. 2 and 3). The expression of Eph receptors A is increased (e.g., EphA2 in the liver and lung at phase 2; Figs. 4, 5, and 7) when the expression of their ligands is decreased (ephrin-A1 in the liver and lung at phase 2; Fig. 2). The expression of Eph receptors B is decreased (e.g., EphB3 in the liver at phase 2; Figs. 4 and 7) when the expression of their ligands is increased (ephrin-B2 in the liver at phase 2; Fig. 3). Such coordinated,
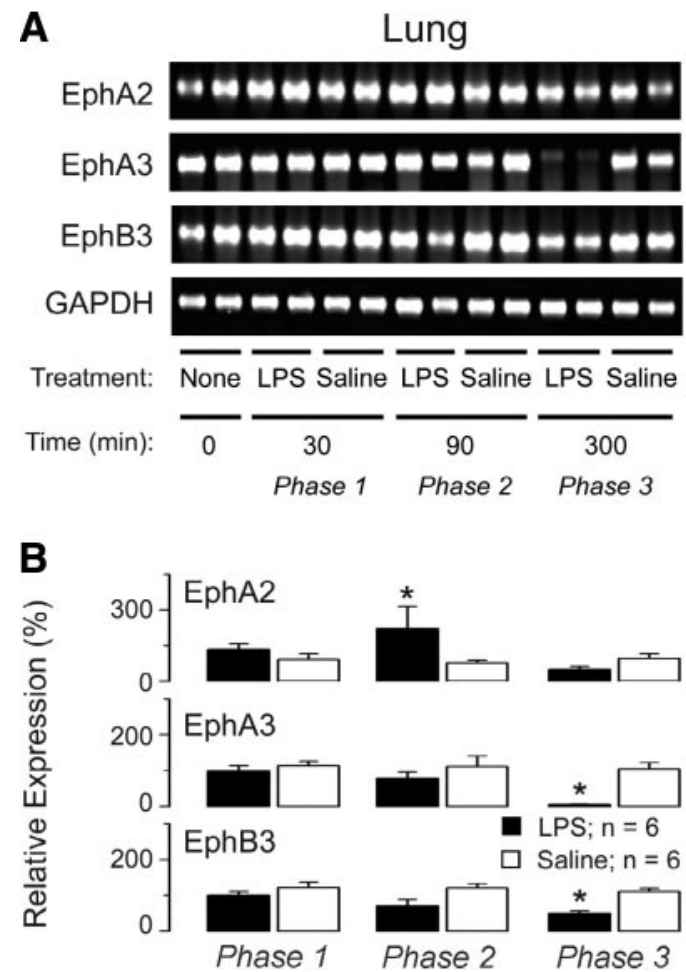

Fig. 5. Effects of LPS and saline on the expression of genes encoding selected Eph receptors in the lung: representative electrophoretograms $(A)$ and the mean relative expression $(B)$. For details, see the legend to Fig. 2 . $* P<0.05$. 
A
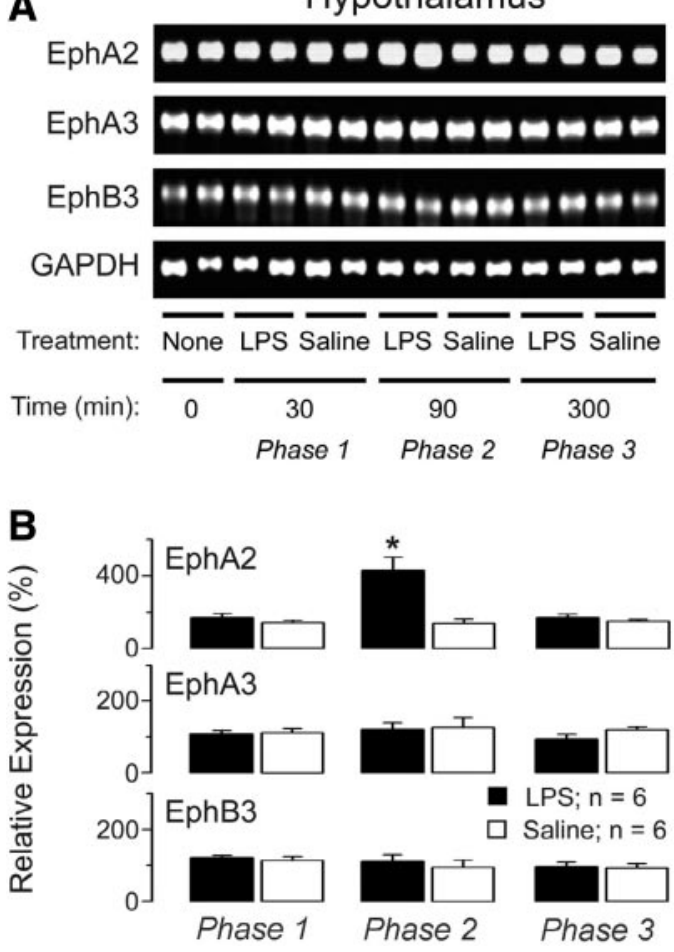

Fig. 6. Effects of LPS and saline on the expression of genes encoding selected Eph receptors in the hypothalamus: representative electrophoretograms $(A)$ and the mean relative expression $(B)$. For details, see the legend to Fig. $2 .{ }^{*} P<0.05$.

counter-directional changes in the transcript levels of an ephrin ligand and its corresponding receptor have been observed in several earlier studies in cell culture. For example, proinflammatory cytokines stimulate the expression of ephrin-A5 (22) but suppress the expression of the EphA3 receptor (21) in rat cardiomyocytes. The initial decrease in the mRNA level of ephrin-A1 in epithelial cells treated with IL-1 $\beta$ and IL-2 is accompanied by a drastic increase in the expression of its receptor, EphA2 (41). In the same model, an increase in the expression of ephrin-A1 occurs after a few hours of incubation with proinflammatory cytokines; this increase is synchronized with a decline in the expression of the EphA2 receptor (41). Because the physiological effect of an ephrin-Eph interaction (cell repulsion vs. attraction) likely depends on the concentrations of the ligand and receptor involved $(19,30)$, the counterdirectional changes in the expression of ephrins and Eph receptors may serve to determine the predominant effect of their activation. It is also of interest that mutually suppressing effects of ephrin-A ligands and EphA receptors have been observed at the protein level. Eph receptor binding has been reported to cause proteolytic cleavage of the cell surfaceexpressed ephrin-A2, and such downregulation of the ligand has been proposed to turn an attraction of the interacting cells into their repulsion (15). Ephrin-A1 stimulation of T cells has been found to decrease the surface expression of endogenous EphA receptors and cause proteosome-dependent degradation of the EphA3 receptor (44).

\section{Biological Significance}

Transcriptional upregulation of Eph receptors. At phase 2 of LPS fever, the EphA2 receptor was overexpressed both at the mRNA level (in all organs studied; Figs. 4-6) and at protein level (in the liver; Fig. 7). Activation of Eph receptors usually (although not always) results in the repulsion of the interacting cells $(15,19,30,47)$. When epithelial or endothelial cells are involved (these cell types are rich in ephrins and Eph receptors; see Refs. 4, 25, 32, 35, 41), such a repulsion can disrupt vascular and tissue barriers and increase their permeability. For example, the EphA2 receptor is involved in the control of the permeability of the intestinal epithelium (41). LPS and proinflammatory cytokines are also known to disrupt endothelial and epithelial barriers and increase their permeability (reviewed in Refs. 2, 3, 45). Furthermore, there is a remarkable similarity in the intracellular signaling events underlying LPS-induced disruption of the endothelial barrier and those taking place after activation of Eph receptors by ephrins. The disruption of endothelial barriers by LPS involves a series of events: activation of yet-unknown tyrosine kinases, activa-
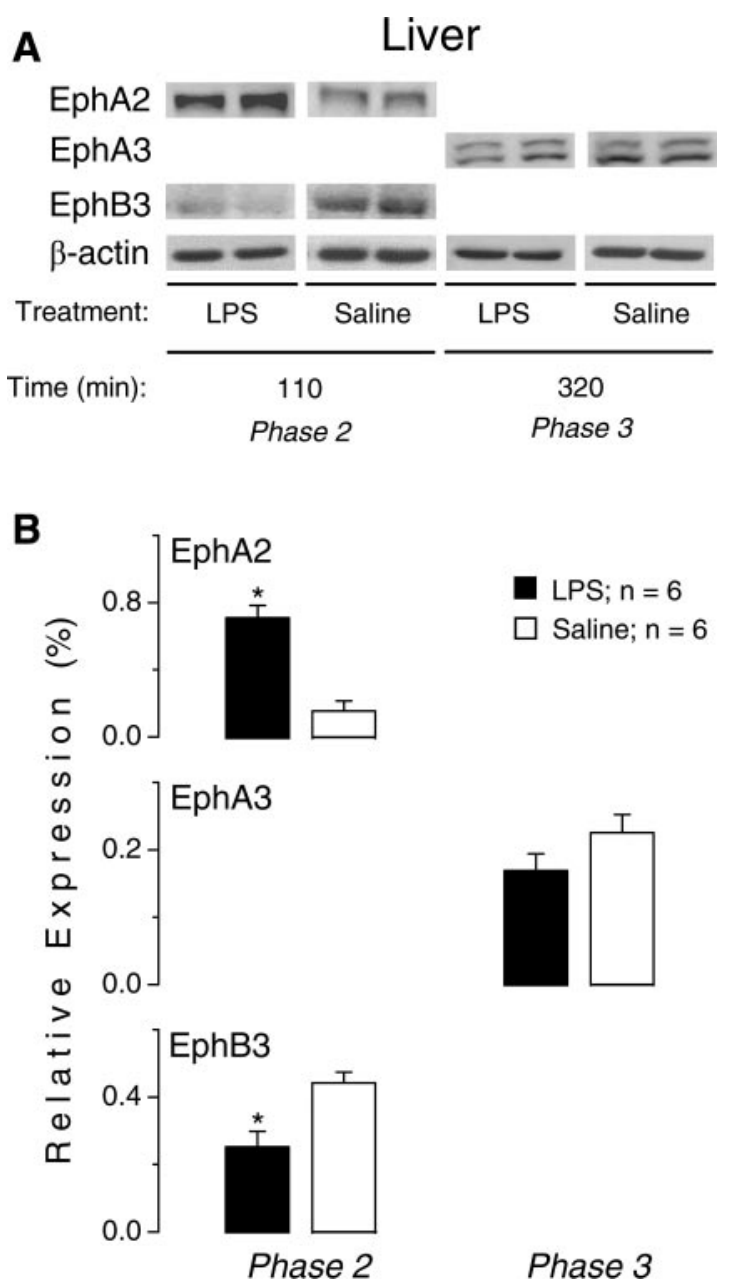

Fig. 7. Effects of LPS and saline on the expression of Eph receptors in the liver at the protein level: representative electrophoretograms $(A)$ and the mean relative expression $(B)$. A: electrophoretograms of 4 samples obtained from rats treated with LPS $(50 \mu \mathrm{g} / \mathrm{kg}$ iv) or saline $(1 \mathrm{ml} / \mathrm{kg}$ iv). Time is the time elapsed after LPS or saline injection; phases are the corresponding phases of the febrile response to LPS. $B$ : each bar is the mean of 6 individual data points, where each datum represents the relative expression of the protein of interest calculated as the ratio between the intensities of 2 immunoblotting bands of the same tissue sample: 1 corresponding to the protein of interest and the other to $\beta$-actin (see Data Processing and Analysis). $* P<0.05$. 
tion of Rho GTPases, reorganization of actin cytoskeleton, and cytosolic internalization of adherens- and tight-junction proteins $(2,3,45)$. Eph receptors are tyrosine kinases, and their interaction with ephrin ligands leads to activation of Rho GTPases (reviewed in Ref. 30) and induces reorganization of F-actin in endothelial and epithelial cells $(4,9)$. Moreover, several recent studies demonstrated a spatial or functional association of Eph receptors with junctional proteins Ecadherin, $\beta$-catenin, and afadin $(4,7,12,34,50)$. Interestingly, the early upregulation of the EphA2 receptor found in the present study at both the mRNA and protein levels immediately precedes the LPS-induced increase in endothelial permeability, which is detectable in rats starting at $2 \mathrm{~h}$ post-LPS (3).

Transcriptional downregulation of Eph receptors. At phase 3 of LPS fever, the expression of EphA1 and EphB4 receptors was downregulated in the liver, and the expression of EphA3 and EphB3 receptors was downregulated in both the liver and lung (Figs. 4 and 5). Because activation of Eph receptors usually leads to cell repulsion $(19,30,47)$, their transcriptional downregulation in inflamed tissues likely promotes cell-cell adhesion. The adhesion of blood leukocytes to the vascular endothelium with the subsequent extravasation and tissue transmigration is a classical example of a cellular event in systemic inflammation $(26,28)$. There are several lines of evidence supporting the involvement of Eph receptors and ephrins in inflammatory trafficking of leukocytes. First, Eph receptors and ephrins are expressed on both cell types involved: leukocytes $(1,49)$ and endotheliocytes $(11,13,14,32$, $33)$. Second, adhesion and transmigration of leukocytes require activation of their surface adhesive molecules, integrins (24, 48). Signaling through several Eph receptors has been shown to affect integrin activity $(29,51)$. Third, activation of EphA receptors has been recently shown to block the migration of T-lymphocytes in vitro (43).

In perspective, the present work shows that a dose of intravenous LPS known to evoke a triphasic fever in the rat $(17,18,39,46)$ causes profound, tissue-specific, and coordinated changes in the mRNA expression of several ephrins (A1, $\mathrm{A} 3$, and B2) and Eph receptors (EphA1, EphA2, EphA3, EphB3, and EphB4; the changes in expression of EphA2 and EphB3 are confirmed at the protein level). Febrile phase 2 is associated with downregulation of ephrin-A1 in the liver and lung and upregulation of its receptor EphA2 in all organs studied; these changes seem to agree with an increased permeability of endothelial or epithelial barriers. Phase 3 is associated with upregulation of ephrins-A1 and -A3 and downregulation of the EphA1 receptor in the liver and the EphA3 receptor in the liver and lung; these changes agree with the known mechanisms of transendothelial and transepithelial migration of leukocytes into inflamed tissues. Therefore, the found changes at the mRNA and protein levels suggest that ephrins and Eph receptors may regulate the permeability of tissue barriers at earlier stages and promote leukocyte trafficking at later stages of systemic inflammation in adult mammals. If this previously unrecognized function is confirmed by future experiments, ephrins and Eph receptors may constitute novel targets for anti-inflammatory therapy with different temporal "windows of opportunity."

\section{ACKNOWLEDGMENTS}

We thank Dr. N. Sambuughin for help with DNA sequencing; R. S. Pero, S. McWilliams, and J. L. Roberts for technical assistance; F. E. Farmer and K. P. Scarff for graphic assistance; and F. E. Farmer and Dr. V. F. Turek for reading an early version of the manuscript and providing important feedback.

\section{GRANTS}

The study was supported in part by National Institute of Neurological Disorders and Stroke Grant NS-41233 (A. A. Romanovsky).

\section{REFERENCES}

1. Aasheim HC, Terstappen LW, and Logtenberg T. Regulated expression of the Eph-related receptor tyrosine kinase Hek11 in early human B lymphopoiesis. Blood 90: 3613-3622, 1997.

2. Aepfelbacher M and Essler M. Disturbance of endothelial barrier function by bacterial toxins and atherogenic mediators: a role for Rho/Rho kinase. Cell Microbiol 3: 649-658, 2001.

3. Bannerman DD and Goldblum SE. Direct effects of endotoxin on the endothelium: barrier function and injury. Lab Invest 79: 1181-1199, 1999.

4. Battle E, Henderson JT, Beghtel H, van den Born MMW, Sancho E, Huls G, Meeldijk J, Robertson J, van de Wetering M, Pawson T, and Clevers H. $\beta$-Catenin and TCF mediate cell positioning in the intestinal epithelium by controlling the expression of EphB/ephrinB. Cell 111: 251-263, 2002.

5. Beckmann MP, Cerretti DP, Baum P, Vanden Bos T, James L, Farrah T, Kozlosky C, Hollingsworth T, Shilling H, Maraskovsky E, Fletcher FA, Lhotak V, Pawson T, and Lyman SD. Molecular characterization of a family of ligands for eph-related tyrosine kinase receptors. EMBO J 13: 3757-3762, 1994.

6. Biervert C, Horvath E, and Fahrig T. Semiquantitative expression analysis of ephrin-receptor tyrosine kinase mRNAs in a rat model of traumatic brain injury. Neurosci Lett 315: 25-28, 2001.

7. Buchert M, Schneider S, Maskenaite V, Adams MT, Canaani E, Baechi T, Moelling K, and Hovens CM. The junction-associated protein AF-6 interacts and clusters with specific receptor tyrosine kinases at specialized sites of cell-cell contact in the brain. J Cell Biol 144: 361-371, 1999.

8. Bustin SA. Absolute quantification of mRNA using real time reverse transcription polymerase chain reaction assay. J Mol Endocrinol 25: 169-193, 2000.

9. Carter N, Nakamoto T, Hirai H, and Hunter T. EphrinA1-induced cytoskeletal re-organization requires FAK and p130 cas . Nat Cell Biol 4: 565-573, 2002.

10. Cheng N, Brantley DM, and Chen J. The ephrins and Eph receptors in angiogenesis. Cytokine Growth Factor Rev 13: 75-85, 2002.

11. Cheng $\mathbf{N}$ and Chen J. Tumor necrosis factor- $\alpha$ induction of endothelial ephrin A1 expression is mediated by a p38 MAPK- and SAPK/JNKdependent but nuclear factor-кB-independent mechanism. J Biol Chem 276: 13771-13777, 2001.

12. Cowan CA and Henkemeyer M. Ephrins in reverse, park and drive. Trends Cell Biol 12: 339-346, 2002.

13. De Silva D and Wittwer CT. Monitoring hybridization during polymerase chain reaction. J Chromatogr B Biomed Sci Appl 741: 3-13, 2000.

14. Dixit VM, Green S, Sarma V, Holzman LB, Wolf FW, O'Rourke K, Ward P, Prochownik EV, and Marks RM. Tumor necrosis factor- $\alpha$ induction of novel gene product in human endothelial cells including a macrophage-specific chemotaxin. J Biol Chem 265: 2973-2978, 1990.

15. Hattori M, Osterfield M, and Flanagan JG. Regulated cleavage of a contact-mediated axon repellent. Science 289: 1360-1365, 2000.

16. Holzman LB, Marks RM, and Dixit VM. A novel immediate-early response gene of endothelium is induced by cytokines and encodes a secreted protein. Mol Cell Biol 10: 5830-5838, 1990.

17. Ivanov AI, Pero RS, Scheck AC, and Romanovsky AA. Prostaglandin $\mathrm{E}_{2}$-synthesizing enzymes in lipopolysaccharide fever: differential transcriptional regulation. Am J Physiol Regul Integr Comp Physiol 283: R1104-R1117, 2002.

18. Ivanov AI, Scheck AC, and Romanovsky AA. Expression of genes controlling transport and catabolism of prostaglandin $\mathrm{E}_{2}$ in lipopolysaccharide fever. Am J Physiol Regul Integr Comp Physiol 284: R698-R706, 2003.

19. Kullander K and Klein R. Mechanisms and functions of Eph and ephrin signaling. Nat Rev Mol Cell Biol 3: 475-486, 2002. 
20. Lai KO, Ip FCF, and Ip NY. Identification and characterization of splice variants of ephrin-A3 and ephrin-A5. FEBS Lett 458: 265-269, 1999.

21. Li YY, McTiernan CF, and Feldman AM. IL-1 $\beta$ alters the expression of the receptor tyrosine kinase gene r-EphA3 in neonatal rat cardiomyocytes. Am J Physiol Heart Circ Physiol 274: H331-H341, 1998.

22. Li YY, Mi Z, Feng Y, McTiernan CF, Zhou R, Robbins PD, Watkins SC, and Feldman AM. Differential effects of overexpression of two forms of ephrin-A5 on neonatal rat cardiomyocytes. Am J Physiol Heart Circ Physiol 281: H2738-H2746, 2001.

23. Liang $\mathbf{P}$ and Pardee AB. Differential display of eukaryotic messenger RNA by means of the polymerase chain reaction. Science 257: 967-971, 1992.

24. Lindbom $\mathbf{L}$ and Werr $\mathbf{J}$. Integrin-dependent neutrophil migration in extravascular tissue. Semin Immunol 14: 115-121, 2002.

25. Liu W, Ahmad SA, Jung YD, Reinmuth N, Fan F, Bucana CD, and Ellis LM. Coexpression of ephrin-Bs and their receptors in colon carcinoma. Cancer 94: 934-939, 2002.

26. Luster A. Mechanisms of disease: chemokines-chemotactic cytokines that mediate inflammation. $N$ Engl J Med 338: 436-445, 1998.

27. Matsunaga T, Greene MI, and Davis JG. Distinct expression patterns of Eph receptors and ephrins relate to the structural organization of the adult rat peripheral vestibular system. Eur J Neurosci 12: 1599-1616, 2000.

28. McIntyre TM, Prescott SM, Weyrich AS, and Zimmerman GA. Cell-cell interactions: leukocyte-endothelial interactions. Curr Opin $\mathrm{He}-$ matol 10: 150-158, 2003.

29. Miao H, Burnett E, Kinch M, Simon E, and Wang B. Activation of EphA2 kinase suppresses integrin function and causes focal-adhesion kinase dephosphorylation. Nat Cell Biol 2: 62-69, 2000.

30. Mural KK and Pasquale EB. 'Eph'ective signaling: forward, reverse and crosstalk. J Cell Sci 116: 2823-2832, 2003.

31. Naraba H, Murakami M, Matsumoto H, Shimbara S, Ueno A, Kudo I, and Oh-ishi S. Segregated coupling of phospholipases $\mathrm{A}_{2}$, cyclooxygenases and terminal prostanoid synthases in different phases of prostanoid biosynthesis in rat peritoneal macrophages. J Immunol 160: 2974 2982, 1998.

32. Oike Y, Ito Y, Hamada K, Zhang XQ, Miyata K, Arai F, Inada T, Araki K, Nakagata N, Takeya M, Kisanuki YY, Yanagisawa M, Gale NW, and Suda T. Regulation of vasculogenesis and angiogenesis by EphB/ephrin-B2 signaling between endothelial cells and surrounding mesenchymal cells. Blood 100: 1326-1333, 2002.

33. Oka T, Oka K, Kobayashi T, Sugimoto Y, Ichikawa A, Ushikubi F, Narumiya S, and Saper CB. Characteristics of thermoregulatory and febrile responses in mice deficient in prostaglandin EP1 and EP3 receptors. J Physiol 551: 945-954, 2003.

34. Orsulic S and Kemler R. Expression of Eph receptors and ephrins is differentially regulated by E-cadherin. J Cell Sci 113: 1793-1802, 2000.

35. Robert B and Abrahamson DR. Control of glomerular capillary development by growth factor/receptor kinases. Pediatr Nephrol 16: 294-301, 2001.

36. Romanovsky AA. Signaling the brain in the early sickness syndrome: are sensory nerves involved? Front Biosci 9: 494-504, 2004.
37. Romanovsky AA, Ivanov AI, and Shimansky YP. Selected contribution: ambient temperature for experiments in rats: a new method for determining the zone of thermal neutrality. J Appl Physiol 92: 2667-2679, 2002.

38. Romanovsky AA, Kulchitsky VA, Akulich NV, Koulchitsky SV, Simons CT, Sessler DI, and Gourine VN. First and second phases of biphasic fever: two sequential stages of the sickness syndrome? Am J Physiol Regul Integr Comp Physiol 271: R244-R253, 1996.

39. Romanovsky AA, Kulchitsky VA, Simons CT, and Sugimoto N. Methodology of fever research: why are polyphasic fevers often thought to be biphasic? Am J Physiol Regul Integr Comp Physiol 275: R332-R338, 1998.

40. Romanovsky AA, Simons CT, and Kulchitsky VA. "Biphasic" fevers often consist of more than two phases. Am J Physiol Regul Integr Comp Physiol 275: R323-R331, 1998.

41. Rosenberg IM, Goke M, Kanai M, Reinecker HC, and Podolsky DK. Epithelial cell kinase-B1: an autocrine loop modulation intestinal epithelial migration and barrier function. Am J Physiol Gastrointest Liver Physiol 273: G824-G832, 1997.

42. Rudaya AY, Steiner AA, and Romanovsky AA. Fever in the mouse: dose dependence of the febrile response of freely moving mice to IV lipopolysaccharide (LPS) at thermoneutrality. In: Program/Abstract No. 7034 Experimental Biology 2004: Abstract Search and Itinerary Builder. Bethesda, MD: FASEB. CD-ROM.

43. Sharfe N, Freywald A, Toro A, Dadi H, and Roifman C. Ephrin stimulation modulates T cell chemotaxis. Eur J Immunol 32: 3745-3755, 2002.

44. Sharfe N, Freywald A, Toro A, and Roifman C. Ephrin-A1 induces $\mathrm{c}-\mathrm{Cbl}$ phosphorylation and EphA receptor downregulation in $\mathrm{T}$ cells. J Immunol 170: 6024-6032, 2003.

45. Stevens T, Garcia JGN, Shasby DM, Bhattacharaya J, and Malik AB. Mechanisms regulating endothelial cell barrier function. Am J Physiol Lung Cell Mol Physiol 279: L419-L422, 2000.

46. Székely M, Balaskó M, Kulchitsky VA, Simons CT, Ivanov AI, and Romanovsky AA. Multiple neural mechanisms of fever. Auton Neurosci 85: 78-82, 2000.

47. Wilkinson DG. Eph receptors and ephrins: regulators of guidance and assembly. Int Rev Cytol 196: 177-244, 2000.

48. Worthylake RA and Burridge K. Leukocyte transendothelial migration: orchestrating the underlying molecular machinery. Curr Opin Cell Biol 13: 569-577, 2001.

49. Yu G, Luo H, Wu Y, and Wu J. Ephrin B2 induces T cell costimulation. J Immunol 171: 106-114, 2003.

50. Zantek ND, Azimi M, Fedor-Chaiken M, Wang B, Brackenbury R, and Kinch MS. E-cadherin regulates the function of the EphA2 receptor tyrosine kinase. Cell Growth Differ 10: 629-638, 1999.

51. Zou JX, Wang B, Kalo MS, Zisch AH, Pasquale EB, and Ruoslahti E. An Eph receptor regulates integrin activity through R-Ras. Proc Natl Acad Sci USA 96: 13813-13818, 1999. 